\title{
Production Enhancement of Vincristine and Vinblastine Compounds in Catharanthus Roseus by Pathogenic and Nonpathogenic Plant Fungi
}

\author{
Bashair Kareem Hasan ${ }^{1}$, Ali F. Merjan ${ }^{2}$ and Salih Abdul Mahdi ${ }^{3}$ \\ ${ }^{1,2,3}$ college of Biotechnology/AL-Qasim Green University-Iraq \\ Corresponding author email: bashayir.k@biotech.uoqasim.edu
}

\begin{abstract}
Plants are an important source of bioactive compounds, in particular Anti-cancer programs that may be linked to Plant productsphytochemicals Vinblastine and Vincristine $\mathrm{mg} / \mathrm{L}$ are alkaloids derived from the Madagascar periwinkle plant Catharanthus roseus. These compounds have cell cycle-specific activity in the M phase, which is consistent with their ability to inhibit tubulin polymerization and prevent formation of the mitotic spindle. So in this study we evaluated the effects of several pathogenic and non-pathogenic fungi such as Alternaria alternate, Exserohilum rostratum on outcome production of Vinblastine and Vincristine in the Catharanthus roseus plant. The present study included several tests involved molecular diagnostic and assessment of fungal pathogenicity by using of polymerase chain reaction (PCR) and Bio-agent indicator techniques respectively, additional to estimation of outcome production of vinblastine and vincristine by using of High-performance liquid chromatography (HPLC) that is a chromatographic method used to estimate of vinblastine and vincristine after the plant infection of Catharanthus roseus plant with the fungi described above.Our result showed significant differences between the two fungi, as the results revealed that the fungus it was found that Alternaria alternate decresed the outcome of vinblastine and vincristine production $(122.7 \mathrm{mg} / 1$ and $153.8 \mathrm{mg} / \mathrm{l})$ respectively compared with control (150 and 160) mg/l respectively. Concerning Exserohilum rostratum the results were counterproductive, as the fungus in question increased the final product of vinblastine and vincristine. It was found that the amount was $(175 \mathrm{mg} / \mathrm{L}$ and $181.3 \mathrm{mg} / \mathrm{L})$ for vinblastine and vincristine respectively.
\end{abstract}

KEYWORDS:CATHARANTHUSROSEUS,ALTERNARIAALTERNATE,EXSEROHILUMROSTRATUM,VINBLASTINE AND VINCRISTINE.

\section{INTRODUCTION}

Plants constitute a significant source of bioactive chemicals, notably anti-cancer programs that may be connected to plant products - plant chemistry in comparison with standard treatment techniques (J. Iqbal et. al. (2017)) offer quick, environmentally safe, rapid, low-cost, andLess toxic treatments. For eg, Catharanthus roseus (S. Leylaie et. al. (2018)), several plants in the Apocynacean family were used for medicinal purposes. This plant has many

Biosc Biotech Res Comm P-ISSN: 0974-6455 E-ISSN: 2321-4007

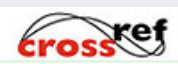

Identifiers and Pagination

Year: 2021 Vol: 14 No (7) Special Issue

Pages: 252-257

This is an open access article under Creative

Commons License Attribn 4.0 Intl (CC-BY).

DOI: $h$ ttp://dx.doi.org/10.21786/bbrc/14.7.56 advantageous features, such as antidiabetic products, bactericides and antihypertensive activity. The primary concern is the terpenoid alkaloids which have been identified in more than 130. For example, vinblastine and vincristine in Catharanthus plant are now in use in cancer treatments (R. van der Heijden et. al. (2004)) Vinca alkaloid is estimated to be more bioavailable than the chemical compound (F. Ferreres et. al. (2008)) and is given as a whole plant extract.

This compound of this plants are very costly because of their limited volumes of indolent alkaloids. In the seasonal fluctuations in plant harvest and growth conditions are not only limited to the available natural supplies and the potential extinction of plants. There are also problems in extracting secondary metabolites from areas of the cultivated plant and in not standardizing the final products (D. Hasa et. al. (2013)). Active trials in higher quantities of strategy
Article Information

Received: $11^{\text {th }}$ May 2021 Accepted after revision: $14^{\text {th }}$ July 2021 
for producing alkaloids (L. Korkina et. al. (2012)) are in the process of overcoming named problems with various extraction procedures (L. Almagro (2015), H.N.T. Pham (2018)). The color variation of its flowers shows the varieties and biological features of plants. Catharanthus roseus aquatic extracts Modern medication was also used to discourage Certain conditions, such as bleeding, diabetes and fever Malaria, heart failure, and cancer complications with the stomach (H.N.T. Pham et. al. (2018)). There is consensus that fungi formed over a billion years ago (Parfrey et. al. (2011)), based on molecular estimates. Plants were most likely associated with the colonization of soil more than 425 million years ago.

More than 10,000 fungal types are considered to be living plants. fungal plant interactions can be classified on the basis of the many ways in which host plants infect, colonize, and how fungus exploit plants as a source of food. Without a host plant, some fungal species may not exist and is known as mandatory bio-food. mandatory bio plants do not usually grow on live plants only and cannot be grown with the Marble Autophagy stage. Necroptosis is a fungus that derives its nutrimen from dead tissue. These have routes in place for host tissue devastation and culturing before to infection and colonization. Hemibiothrophages are referred to as other fungal species that may comprise both biotic and necrotic feeding phases throughout their lifetime.Certain fungal species cannot survive without a host plant and are known as mandatory biotrophies (M.L. Pawlowski et. al. (2016)). Several experiments have been carried out to classify these alkaloids using different techniques, such as high performance liquid chromatography (HPLC). (M.L. Pawlowski et. al. (2016).

In present study, vinblastine and vincristine concentrations in the leaves of two wild Catharanthus roseus species with pink and white flowers were investigated and compared; In order to distinguish and quantify vinblastine and vincristine concentrations before and after treatment with various isolates of pathogenic and nonpathogenic fungi, a simple, quick and validated HPLC method had been used.

\section{MATERIAL AND METHODS}

This study was conducted in the Laboratory of Plant Tissue Culture, Department of Biotechnology, College of Biotechnology, Al-QasimGreen University, Iraq.

fungusIsolates: pathogen and nonpathogenic fungus have been isolated from leaf spots of Catharanthus roseus plant infected from Al-Hillah nurseries. All collected Leaves surface it has been sterilized by immersing it in (1\%) percent sodium hypochlorite solution for two minutes and then washing it with clean distilled water. They were dried by putting them between two filter papers then culture in petri dishes containing potato dextrose agar (PDA) medium containing the antibiotic Tetracycline and ampicillin $10 \mathrm{mg}$ / $\mathrm{L}$ and then the dishes were incubated in the incubator at $25^{\circ} \mathrm{C}$ for one week (Aneja, 2004). (Figure.1).

Microscopic identification: Microscopic diagnosis of isolates it has been done according to T., Watanabe. (2002).
Although various publications regarding soil, seed and plant fungi are accessible, Tsuneo Watanabe's book provides the finest information on isolation, cultivation, and soil, seed or plant fungal methods. (Tsuneo Watanabe et. al. (2002)).

\subsection{The molecular classification of isolation, DNA} Sequencing of PCR amplicons: The resolved PCR amplicons were commercially sequenced from termini, forward and reverse directions, according to instruction manuals of the sequencing company (Macrogen Inc. Geumchen, Seoul, South Korea). Only clear chromatographs obtained from ABI sequence files were further analyzed, ensuring that the annotation and variations are not because of PCR or sequencing artifacts. By comparing the observed nucleic acid sequences of fungal samples with the retrieved reference sequences of the fungal database, the virtual positions, and other details of the retrieved PCR fragments were identified.

2.4. Interpretation of sequencing data: The sequencing results of the PCR products were edited, aligned, and analyzed as long as with the respective sequences in the reference database using Bio Edit Sequence Alignment Editor Software Version 7.1 (DNASTAR, Madison, WI, USA). The observed nucleic acids were numbered in PCR amplicons as well as in their corresponding positions within the referring genome. Each detected variant within the targeted ribosomal sequences was annotated by SnapGene Viewer ver. 4.0.4 (https://www.snapgene.com).

2.5. Fungus Pathogenicity test: Fungus pathogenicity tests were achieved according to the Intentional seed testing association (1999). The plates were incubated at $27^{\circ} \mathrm{C}$ for 7 days, after that the percentage of seed germination was calculated according to the following formula (Bolken (1974), Haider (1986).

\section{Percentage of seed injury $=\frac{T \text { Denumberofinf ectedseeds }}{T \text { Detotalnumberoftestedseeds }} \times 100$}

2.6. Green House Experiment: To study the effect of pathogenicity on Vinca, a greenhouse experiment was conducted in a nursery in Babylon citythen the percentage of germination was calculated, after one month according to procedure described in (Hira Kaji Manandhar et al.,2016) (Galperin (2003) Hira Kaji Manandhar (2016)) And then calculate the injury severity for each repeat according to the rate:

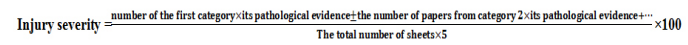

\section{RESULT AND DISCUSSION}

\subsection{Identification of fungi isolates:}

3.1.1: Morphological and Cultural Features of Alternaria alternta and Exserohilum rostratum: in culture, as long chains with dark brown conidiophores, alternaria alternata develops. They flourish in moisture and nutrition conditions that produce asexual spores called conidiospores (conidia) (figure 1).while Exserohilum rostratum awide, dark conidia with transverse septa produced individually, Conidiophores geniculate; 6 to 8 distosepta; 8 to 10 cells (Tsuneo Watanabe (2002)) (figure 2). Microscopic imaging of the fungi was 
performed according to the information, camera type- Nikon D5600, Microscope - LOMO, Illumination - bright field microscopy, Image size- 24 mega pixels, Image technique - Image stack, Lens - Nikon 40x objective lens.

Figure 1: Alternaria alternata Showing ramified acropetal chains, multi-pyriform conidia with small conical beaks.

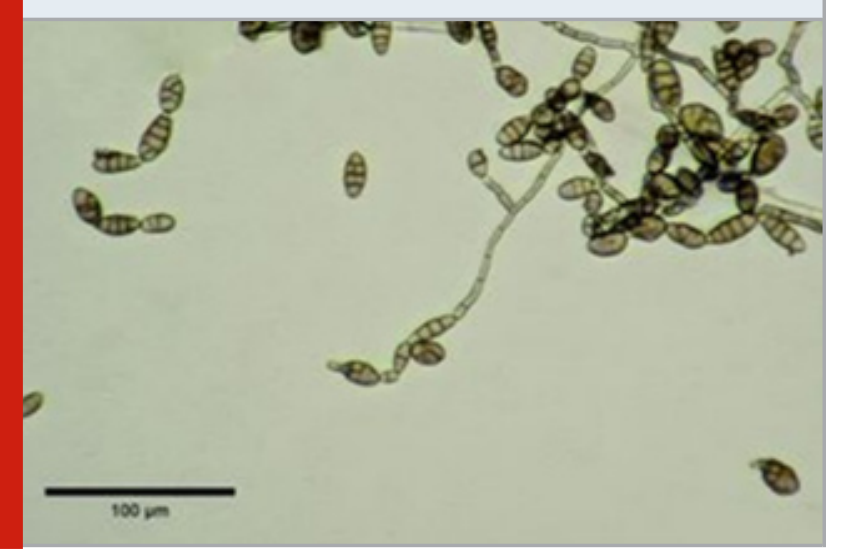

Figure 2: Exserohilum rostratum showing conspicuous dark and septic basal; truncated, outward-looking hilum and multi celled

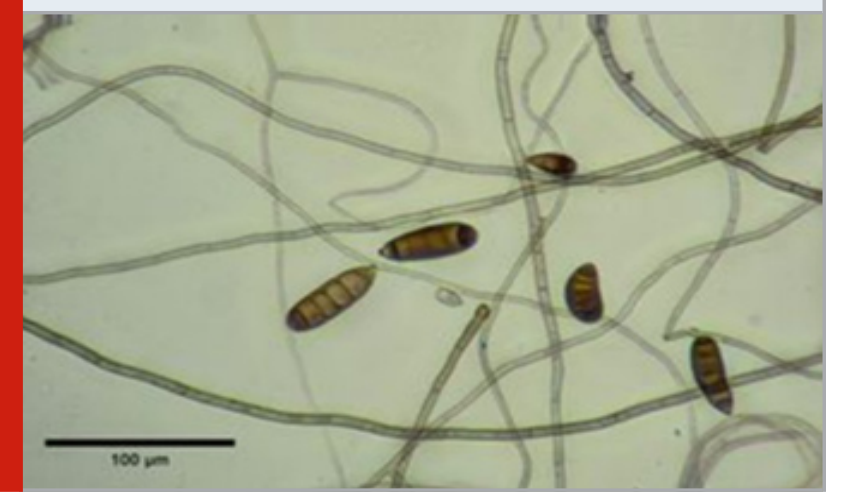

Figure 3: The NCBI BLASTn engine indicated the presence of about $99 \%$ of homology with the Gen Bank accession number KY788022.1 that belonged to Alternaria alternata

Alternaria alternata strain GRSH5 small subunit ribosomal RNA gene, partial sequence; internal transcribed spacer 1,5.8S ribosomal RNA gene, and internal transcribed spacer 2, complete sequence; and large subunit ribosomal RNA gene, partial sequence GenBank k k7780022.1

Generank FASTA Poosest

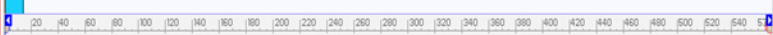

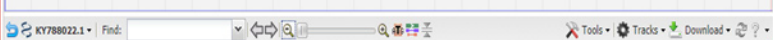
Fill Pans

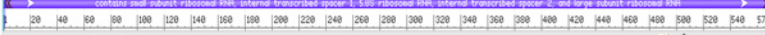

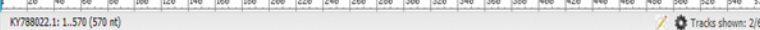
$\Rightarrow$

570 bp PCR amplicon length

3.1.2 Molecular identification of fungus isolates, sequencing PCR: The sequencing reactions indicated the confirmed identity of the amplified products by performing NCBI blastn. The NCBI BLASTn engine showed a high sequence samples of A, Fusarium incarnatum sequences.
The NCBI BLASTn engine showed a high sequence similarity between the sequenced samples of S2, S3, and S8 with Alternaria alternata sequences. The NCBI BLASTn engine indicated the presence of about $99 \%$ of homology with the GenBank accession number KY788022.1 that belonged to Alternaria alternata (Fig. 3). Concerning B, The NCBI BLASTn engine indicated the presence of about $99 \%$ of homology of this fungal sample with the GenBank accession number MT524320.1 that belonged to the rRNA sequences of Exserohilum rostratum (Fig. 4). By comparing the DNA sequences observed of the currently examined samples with the sequences obtained from DNA, specific locations and other information were determined of the recovered PCR fragment.

Figure 4: The NCBI BLASTn engine indicated the presence of about $99 \%$ of homology of this fungal sample with the GenBank accession number MT524320.1 that belonged to the rRNA sequences of Exserohilum rostratum. The blue arrow refers to the starting point of this amplicon while the red arrow refers to its endpoint.

Exserohilum rostratum isolate E21 small subunit ribosomal RNA gene, partial sequence; internal transcribed spacer 1,5.8S ribosomal RNA gene, and internal transcribed spacer 2, complete sequence; and large subunit ribosomal RNA gene, partial sequence Genzank MiT524320.1

Genenens EAST

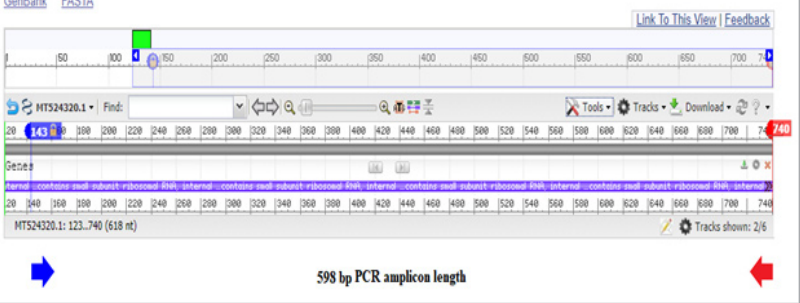

Figure 5: Effect of Alternaria alternata and Exserohilum rostratumon germination percentage of radish seeds; PV $<.001$ and L.S.D $(P V \leq 0.05)=0.809$.

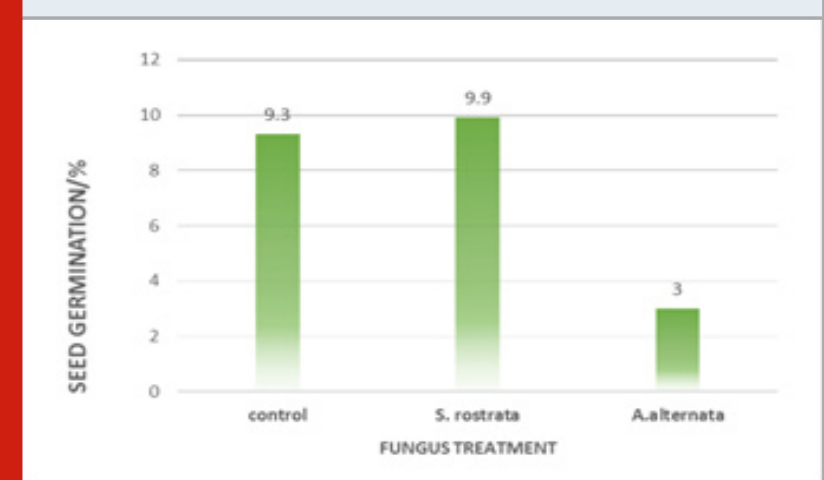

3.1.3Pathogenicity Detection: in present study we tested the pathogenicity of fungus on the seeds of radish according to the Intentional seed testing association (1999). Our results demonstratedclear differences in the effect of fungus isolates. Regarding effecting of Alternaria altanitaon the radish seeds growth, where the percentage of germination was $3 \%$, whilethe effect of nonpathogenic fungal Exserohilum rostratumon same seeds was $9.9 \%$ compared with control.P value $<001$ and L.S.D $(\mathrm{PV} \leq 0.05)$ $=0.809$ (figure 5). Concerning the effect of both fungi on 
the high plants it was fond that alternate fungus showed a significant reduction in the length of the purple flower plants by $30 \mathrm{~cm}$ compared with control $47 \mathrm{~cm}$, whereas the fungus Exserohilum rostratum had been a significant increasing effect on same plant height $60 \mathrm{~cm}$ compared with control figure 6 . Same findings were obtained with white rose figure 7 .

Figure 6: Effecting of both fungus (Alternaria \& Exserohilum) on high plants: purplePV $<.001$ and L.S.D $(\mathrm{PV} \leq \mathbf{0 . 0 5})$ $=2.547$.

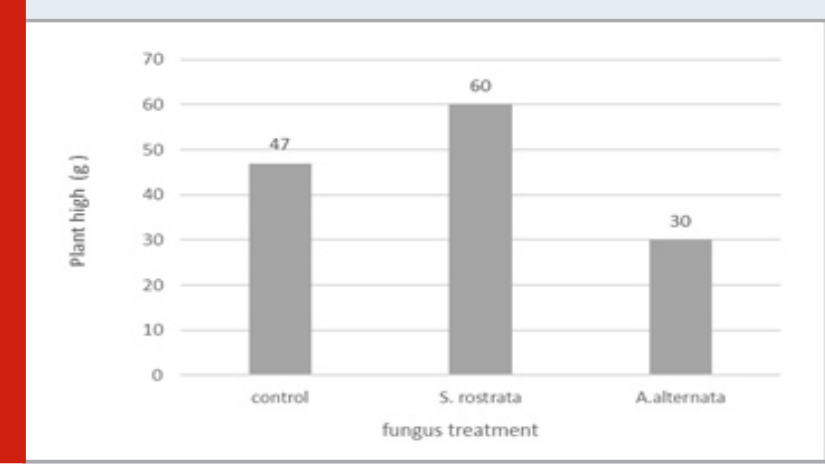

Figure 7: Effecting of both fungus (Alternaria \& Exserohilum) on high plants white rose / cm PV $<.001$ and L.S.D ( PV $\leq$ 0.05) $=\mathbf{2 . 3 4 0}$

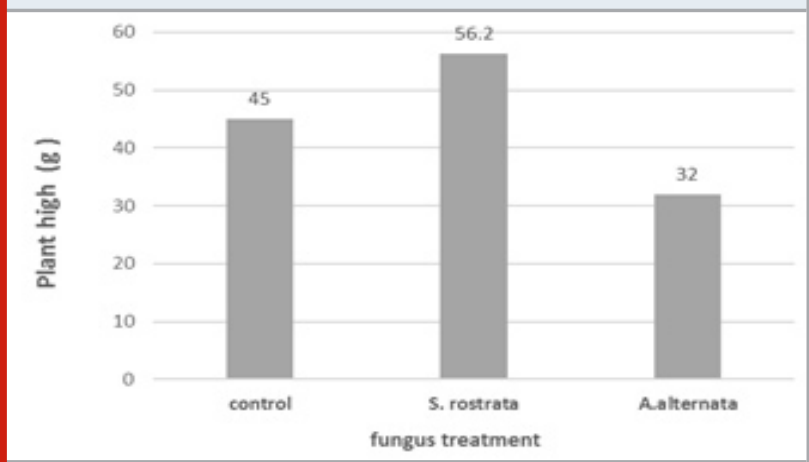

Figure 8: Effect of Alternaria alternata and Exserohilum rostratum fungal onvincristine concentration inproduction in the Purple leaf of Catharanthus roseus by using of HPLC technique. $P V<.001$ and L.S.D $(P V \leq 0.05)=4.837$

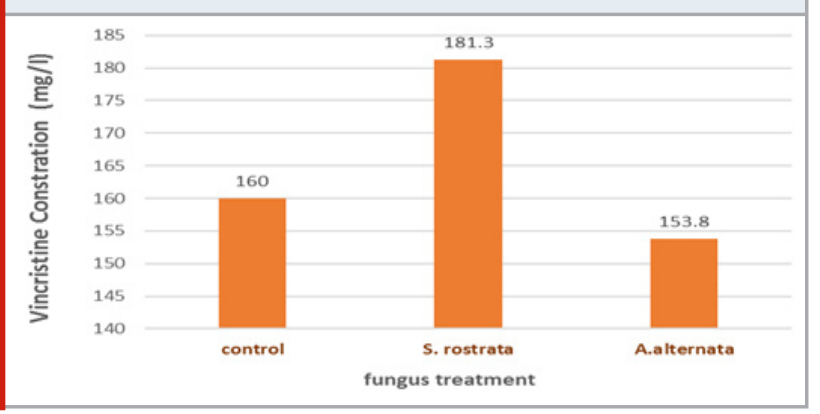

3.1.4: Vinblastine and vincristine: Our findings revealed that the used fungal in current study showed different effects on Vinblastine and vincristine concentrations. It was found that the concentration of vincristine was $181.3 \mathrm{mg} / \mathrm{L}$ in case plant with purple flower, compared with the control (160 $\mathrm{mg} / \mathrm{L}$ ) figure 8 . While its concentration in the plant with white flower was $195.7 \mathrm{mg} / \mathrm{L}$ compared with the control vincristine concentration (180.2 $\mathrm{mg} / \mathrm{L})$ figure 9. Similar results it was found with vinblastine concentrations. 153 and $149 \mathrm{mg} / \mathrm{L}$ for violet and white respectively comparison with the control figure $10 \& 11$.

Figure 9: Effect of Alternaria alternata and Exserohilum rostratum fungal onvincristine concentration inproduction in the white leaf of Catharanthus roseus by using of HPLC techniquePV $<.001$ and L.S.D $(P V \leq 0.05)=5.972$

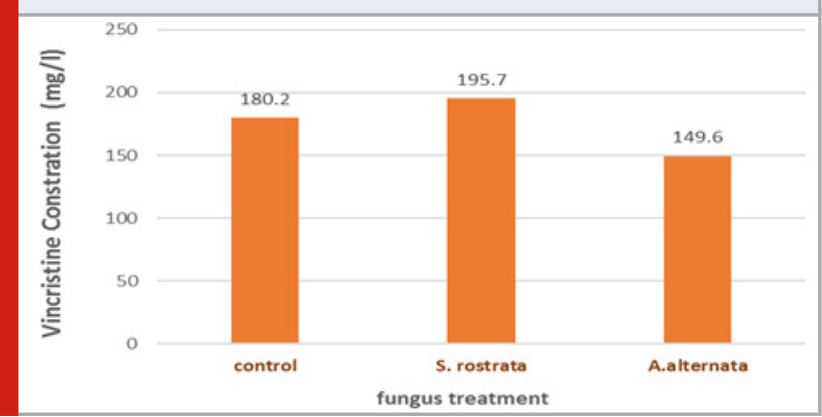

Figure 10: Vinblastine production concentration $\mathrm{mg} / \mathrm{l}$ in Catharanthus roseus with purple flowers $\mathrm{PV}<.001$ and L.S.D $(\mathrm{PV} \leq \mathbf{0 . 0 5})=13.37$

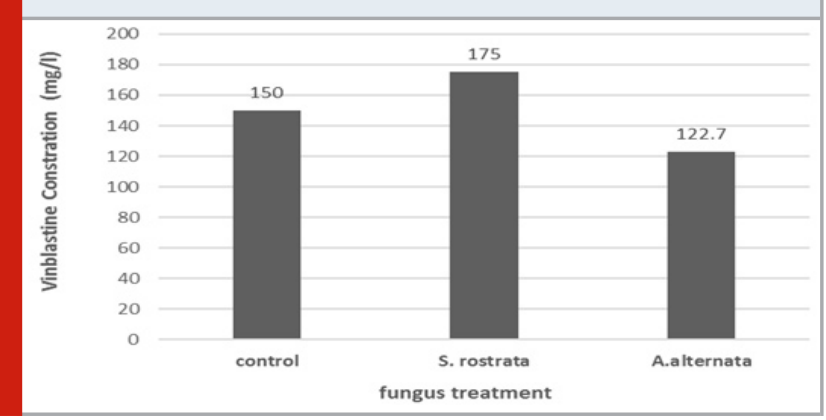

Figure 11: Vinblastine production concentration $\mathrm{mg} / \mathrm{l}$ in Catharanthus roseus with white flowersPV $<.001$ and L.S.D $(\mathrm{PV} \leq \mathbf{0 . 0 5})=\mathbf{1 1 . 2 1}$

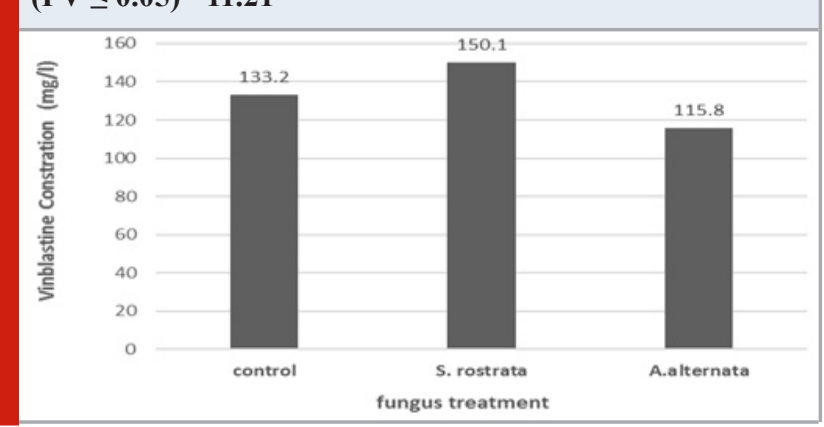

\section{DISCUSSION}

The ANOVA analysis showed a positive and negative significant effect of spraying filtrate of fungi species on the concentration of (vincristine\& vinblastine) in purple and white cultivar of Catharanthus roseus plant. The effects of 
plant fungi in (Catharanthus roseus) varied greatly, some of which had a pathogenic and a negative effect on the plant which is (Alternaria alternata). a fungal pathogen isolated from the symptomatic leavess Catharanthus roseus based on its morphological and molecular properties comparable to $A$. alternata. Alternaria alternata has been documented on a wide range of plant hosts as a fungus that causes many diseases, notably leaf spots and blight.

The reasons for Musa spp., Actinidia deliciosa, Rumex vesicarius and Juglans regia (Parkunan (2013), Corazza (1999), Belisario (1999)) and blight of Zinnia acerosa, Artemisia annua, Incarvillea emodi and Zanthoxylum piperitum (Colbaugh PF (2001, Samanta JN (2009), V. Shanmugam (2011), Yang WX (2013)). Additionally, $A$. alternata was reported as an endophytic fungus on Catharanthus roseus (Kharwar RN (2008), P. Momisa (2013), P.P. Palem (2015)), but the first report of A. alternata causing leaf blight of rosy periwinkle report relating this pathogen in Iraq (Lahuf AA (2019)). Both the plant height and the dry weight of the shoot and root system led to a decreased, as well as in the concentration of the active compounds when calculating the concentration of vincristine and vinblastine using the HPLC technique, also discover that total amino acid content of periwinkle leaves was significantly reduced due to infection of $A$. alternate (L. Kumari (2020)) whose active compound concentration reached very low levels, which has been shown to be highly pathogenic and have a negative impact on the plant's biological pathway and its living processes.

Unlike the other fungi (Exserohilum rostratum), The first report on Exserohilum rostratum associated with rice seeds in Venezuela (R. Cardona (2007)) and in countries neighboring Iraq was considered First record of Exserohilum rostratum as a novel pathogen causing bean blight in Egypt (MfF (2020). However, there is no previous report relating this pathogen to disease on rosy periwinkle plants in Iraq. Hence, this is the first report of E. rostratum don't causing leaf blight of pink or white Catharanthus roseus. which was found to have a non-pathogenic genetic structure far from the rest of the fungi, evidence of different genetic content and has a Positive effect in increasing active compound. The scientific explanation of these conclusions is due to the fact that the pathogen works to stop the vital processes of the plant, such as the cycle of carbs and oxidative phosphorylation, and these processes are responsible for the formation of effective compounds, which leads to their reduction, unlike the non-pathogenic fungus, activating the biological processes of the plant and thus increasing the effective compounds of the plant and making use of them in the treatment of diseases.

\section{CONCLUSION}

1. All fungal isolates showed the ability to produce more than one virulence factor which included (seed germination, Plant high, vincristine and vinblastine concentration).

2. The most effected and pathogenic among fungi isolates were A.altrnata.

3. Exserohilum rostratum were more activated isolates, while all isolates showed highly pathogeny to processes of plant

\section{REFERENCES}

Almagro, L., Fernández-Pérez, F. and Pedreño, M.A., 2015. Indole alkaloids from Catharanthus roseus: bioproduction and their effect on human health. Molecules, 20(2), pp.2973-3000.

Belisario, A., Forti, E., Corazza, L. and Van Kesteren, H.A., 1999. First report of Alternaria alternata causing leaf spot on English walnut. Plant disease, 83(7), pp.696-696.

Bolkan, H.A. and Butler, E.E., 1974. Studies on heterokaryosis and virulence of Rhizoctonia solani. Phytopathology, 64(5), pp.13-522.

Colbaugh, P.F., Mackay, W.A. and George, S., 2001. Alternaria alternata flower blight of Zinnia acerosa in Texas. Plant disease, 85(2), pp.228-228.

Colditz, F., Krajinski, F. and Niehaus, K., 2007. Plant proteomics upon fungal attack. Plant Proteomics, pp.283309.

Corazza, L., Luongo, L. and Parisi, M., 1999. First report of leaf spot caused by Alternaria alternata on kiwifruit in Italy. Plant disease, 83(5), pp.487-487.

Desjardins, A.E., 2006. Fusarium mycotoxins: chemistry, genetics, and biology. American Phytopathological Society (APS Press).

Ezhilarasi, G.D., Latchoumi, T.P. and Balamurugan, K., 2020. UIP - A Smart Web Application to Manage Network Environments, Advances in Intelligent systems and computing book series.

Ferreres, F., Pereira, D.M., Valentão, P., Andrade, P.B., Seabra, R.M. and Sottomayor, M., 2008. New phenolic compounds and antioxidant potential of Catharanthus roseus. Journal of Agricultural and Food Chemistry, 56(21), pp.9967-9974.

Galperin, M., Graf, S. and Kenigsbuch, D., 2003. Seed treatment prevents vertical transmission of Fusarium moniliforme, making a significant contribution to disease control. Phytoparasitica, 31(4), pp.344-352.

Ghosh, D.K., Motghare, M., Kokane, A., Kokane, S., Warghane, A., Bhose, S., Surwase, D. and Ladaniya, M.S., 2019. First report of a 'Candidatus Phytoplasma cynodontis'-related strain (group 16SrXIV) associated with Huanglongbing disease on Citrus grandis. Australasian plant disease notes, 14(1), pp.1-4.

Hasa, D., Perissutti, B., Dall'Acqua, S., Chierotti, M.R., Gobetto, R., Grabnar, I., Cepek, C. and Voinovich, D., 2013. Rationale of using Vinca minor Linne dry extract phytocomplex as a vincamine's oral bioavailability enhancer. European journal of pharmaceutics and biopharmaceutics, 84(1), pp.138-144.

Iqbal, J., Abbasi, B.A., Mahmood, T., Kanwal, S., Ali, B., Shah, S.A. and Khalil, A.T., 2017. Plant-derived anticancer 
agents: A green anticancer approach. Asian Pacific Journal of Tropical Biomedicine, 7(12), pp.1129-1150.

Jacobs, D.I., Snoeijer, W., Hallard, D. and Verpoorte, R., 2004. The Catharanthus alkaloids: pharmacognosy and biotechnology. Current medicinal chemistry, 11(5), pp.607-628.

Kharwar, R.N., Verma, V.C., Strobel, G. and Ezra, D., 2008. The endophytic fungal complex of Catharanthus roseus (L.) G. Don. Current science, pp.228-233.

Korkina, L. and Kostyuk, V., 2012. Biotechnologically produced secondary plant metabolites for cancer treatment and prevention. Current Pharmaceutical Biotechnology, 13(1), pp.265-275.

Ku, Y.S., Cheng, S.S., Gerhardt, A., Cheung, M.Y., Contador, C.A., Poon, L.Y.W. and Lam, H.M., 2020. Secretory peptides as bullets: Effector peptides from pathogens against antimicrobial peptides from soybean. International journal of molecular sciences, 21(23), p.9294.

Leylaie, S. and Zafari, D., 2018. Antiproliferative and antimicrobial activities of secondary metabolites and phylogenetic study of endophytic Trichoderma species from Vinca plants. Frontiers in Microbiology, 9, p.1484. Mishra, P., Jimmy, L., Ogunmola, G.A., Phu, T.V., Jayanthiladevi, A. and Latchoumi, T.P., 2020, December. Hydroponics cultivation using real time iot measurement system. In Journal of Physics: Conference Series (Vol. 1712, No. 1, p. 012040). IOP Publishing.

Momsia, P. and Momsia, T., 2013. Isolation, frequency distribution and diversity of novel fungal endophytes inhabiting leaves of Catharanthus roseus. Int. J. Life Sci. Biotechnol. Pharm. Res, 2(4).

Moretti, A., Susca, A., Mulé, G., Logrieco, A.F. and Proctor, R.H., 2013. Molecular biodiversity of mycotoxigenic fungi that threaten food safety. International journal of food microbiology, 167(1), pp.57-66.

Parkunan, V., Li, S., Fonsah, E.G. and Ji, P., 2013. First report of Alternaria leaf spot of Banana caused by Alternaria alternata in the United States. Plant disease, 97(8), pp.1116-1116.

Parfrey, L.W., Lahr, D.J., Knoll, A.H. and Katz, L.A., 2011. Estimating the timing of early eukaryotic diversification with multigene molecular clocks. Proceedings of the National Academy of Sciences, 108(33), pp.1362413629.

Pham, H.N.T., Sakoff, J.A., Van Vuong, Q., Bowyer, M.C. and Scarlett, C.J., 2019. Phytochemical, antioxidant, antiproliferative and antimicrobial properties of Catharanthus roseus root extract, saponin-enriched and aqueous fractions. Molecular biology reports, 46(3), pp.32653273.

Palem, P.P., Kuriakose, G.C. and Jayabaskaran, C., 2015.
An endophytic fungus, Talaromyces radicus, isolated from Catharanthus roseus, produces vincristine and vinblastine, which induce apoptotic cell death. PloS one, 10(12), p.e0144476.

Pawlowski, M.L. and Hartman, G.L., 2016. Infection mechanisms and colonization patterns of fungi associated with soybean. Fungal pathogenicity, p.25.

Pham, H.N.T., Vuong, Q.V., Bowyer, M.C. and Scarlett, C.J., 2018. Ultrasound-assisted extraction of Catharanthus roseus (L.) G. Don (Patricia White cultivar) stem for maximizing saponin yield and antioxidant capacity. Journal of Food Processing and Preservation, 42(5), p.e13597.

Prasath, S. (2020). Probabilistic Mceliece Public-Key Cryptography Based Identity Authentication For Secured Communication In Vanet. Solid State Technology, 63(6), 10167-10182.

Prasath, S. Validating Data Integrity in Steganographed Images using Embedded Checksum Technique. International Journal of Computer Applications, 975, 8887.

Samanta, J.N., Solanki, B.D. and Mandal, K., 2009. First report of sweet wormwood leaf blight disease in India. Australasian Plant Disease Notes, 4(1), pp.78-79.

Shanmugam, V., Dhyani, D. and Ananthapadmanaban, D., 2011. First report of Alternaria sp. causing blight on Incarvillea emodi. Australasian Plant Disease Notes, 6(1), pp.33-35.

Srivastava, S., Kumar, R., Bindal, S., Singh, V.P., Rana, M., Singh, J.P. and Sinha, A., 2020. Ancient, Mid-Time, and Recent History of Seed Pathology. In Seed-Borne Diseases of Agricultural Crops: Detection, Diagnosis \& Management (pp. 81-103). Springer, Singapore.

Tzortzakis, N.G., 2007. Maintaining postharvest quality of fresh produce with volatile compounds. Innovative food science \& emerging technologies, 8(1), pp.111-116.

Venkata Pavan, M., Karnan, B. and Latchoumi, T.P., 2021. PLA-Cu reinforced composite filament: Preparation and flexural property printed at different machining conditions. Advanced Composite Materials, https://doi. org/10.1080/09243046.2021, 1918608.

Watanabe, T., 2002. Pictorial atlas of soil and seed fungi: morphologies of cultured fungi and key to species. CRC press.

Yang, W.X., Liu, F., Zhang, N., Ren, X.D. and Liu, D.Q., 2013. First report of Alternaria alternata causing blight on Zanthoxylum piperitum in China. Plant disease, 97(6), pp.840-840.

Zhou, L.J., Gabriel, D.W., Duan, Y.P., Halbert, S.E. and Dixon, W.N., 2007. First report of dodder transmission of huanglongbing from naturally infected Murraya paniculata to citrus. Plant Disease, 91(2), pp.227-227. 